\title{
VERSITA
}

\section{The Function of Communication in Faculty Management}

\author{
Osman Ferda Beytekin ${ }^{1}$, Hasan Arslan ${ }^{2}{ }^{*}$
}

${ }^{1}$ Ege University, Faculty of Education, Department of Educational Sciences, Izmir, Turkey

2 Çanakkale Onsekiz Mart University, Faculty of Education, Department of Educational Sciences, Çanakkale, Turkey

KEYWORDS

Communication

Deans

Faculty management

Higher education

\begin{abstract}
This research intends to explain the nature of communication and its strategic role from the perspective of faculty deans. In other words, the aim of the research is to analyze the perspectives of faculty deans on communication and its strategic functional role in the organization. The research theme is clarified by three subquestions: What is the function of communication in the organizations from the perspectives of deans? What are the principal advantages and disadvantages of the communication function in the organizations? Lastly, how does the faculty dean perceive himself/herself as a communicator in the management of the organization? Qualitative approach is applied through ten semistructured interviews of faculty deans in the university. The research findings reveal that the nature and functions of communication in the organization are important and are perceived as a vital element of university management. Moreover, the function of communication is confirmed as a key element to success in the strategic plans and in the organizational context of universities.
\end{abstract}

\section{Introduction}

Managers spend most of their day engaged in communication; in fact, older studies of how much time managers spend on various activities show that communication occupies 70 to 90 percent of their time every day (Mintzberg

\footnotetext{
* Contact addresses: ferda.beytekin@ege.edu.tr (O. F. Beytekin); arslan.phd@gmail.com (H. Arslan)
} 
1973; Eccles and Nohria 1991). Organizational communication can be described as the process by which individuals stimulate meaning in the minds of other individuals, by means of verbal and nonverbal messages in the context of a formal organization (Richmond and McCroskey 2009). Organizational communication helps to generate knowledge, understanding and realization in members of staff in preparation for the acceptance of changes to structures and operations, both inside and outside of the university. Effective communication requires managerial competence in distributing and apprehending the messages. Thus, the essential duty of an administrator is to establish and sustain an effective communication in the organization. Moreover, effective communication encourages motivation of the employees by informing and simplifying their responsibilities. Managers improve their ability to get things done with and through people by communicating more effectively. Every administrator in higher education faces three important communication-related issues (Gratz and Salem 1981). First, the information flow, that is getting the information, disseminating it to the people who need it, restricting the flow to people who do not need it, and improving the efficiency and quality of the process. Second, the information quality, consists of providing communication that is persuasive and motivating and creating the opportunity for communication. Finally and thirdly, it is the communication process itself that determines how communication changes, under what circumstances and at what times particular types of communication are most effective, and how communication influences decision making and decision makers like faculty deans.

Likewise higher education administrators spend most of their time in communication with their superiors, colleagues and subordinates to achieve the goals of planning, organizing, leading and controlling. In this manner, effective communication serves as a critical and strategic tool for administrators to manage their organizations. Effective communication is crucial for academic administrators in higher education so as to fulfil the primary functions of management, i.e., planning, organizing, leading and 
controlling. Communication facilitates the carrying out of management duties and roles by academic administrators. In fact, being able to communicate effectively is what allows an administrator to move into a leadership position.

This research intends to explain the nature of communication and its strategic role from the perspective of faculty deans. In other words, the aim of the research is to analyze the perspectives of faculty deans on communication and its strategic and functional role in the faculty organization. The research theme is clarified by three sub-questions: What is the function of communication in the organizations from the perspectives of deans? What are the principal advantages and disadvantages of the communication function in the organizations? How does the faculty dean perceive himself/herself as a communicator in the management of the organization?

\section{Theoretical Framework}

Universities have to face more complex challenges as external and internal environment keeps changing. Multi-factors challenge faculty motivation, commitment, loyalty, which finally all threaten organizational performance. Moreover, if leadership is a key basis for organizational performance, one can safely say communication is the key to effective leadership (Atwater and Waldman 2008). Effective communication of corporate culture and human resources are the key factors that significantly determine the management of a faculty as well as the development of its strategy, its achievements and position in higher education. Higher education is primarily an informationprocessing system, and communication difficulties are more than nuisances to such a system; they are life-threatening for the organization itself (Gratz and Salem 1981). Organizational communication issues between Deans and Faculty were not only particular to the institution of higher education being studied, but were specifically debatable for the reason that continuing alterations related to changes in personnel and policy in top administration 
of the universities. Faculty deans have to succeed in numerous communication activities with the head of departments, the faculty members, and in the meetings with the Dean's Council within their management duties. Both informal and formal meeting sessions with faculty members show organizational communication processes in faculty management to be an issue within universities. Besides, faculty deans need to provide information to faculty in many areas, and communication is a key to meeting faculty demands.

Organizational structure influences communication patterns within an organization. Communications flow in three directions - downward, upward, and horizontally. Downward communication consists of policies, rules, and procedures that flow from top administration to lower levels. Upward communication consists of the flow of performance reports, grievances, and other information from lower to higher levels. Horizontal communication is essentially coordinative and occurs between departments or divisions on the same level. External communication flows between employees inside the organization and a variety of stakeholders outside the organization (Lunenburg and Ornstein 2008). Organizational communication consists of three primary components: core, managerial, and corporate communication. In core organizational communication, leaders need to be able to write and to speak in the language that is clear, correct, and concise. In addition, they need to be able to create and deliver oral presentations confidently and persuasively, using graphics that contribute to delivering their messages. Managerial communication abilities constitute the core skills of the communication process in organizations. They are the abilities that more directly involve managing others, from one-on-one contact to interacting with groups and the organization. They are the abilities needed to interact with individuals and to manage groups in the organizations. Managerial communication component begins with emotional intelligence or interpersonal skills and an understanding of differences needed to interact effectively with others as individuals or groups. And the last component as corporate communication derives from 
the managerial skills to those skills needed to lead an organization and address a broader community. Communication becomes even more complex when managers move into the position of needing to think about how best to communicate to all internal and external stakeholders (Barrett 2006).

Determinants of communication (Figure 1) in an organization are both a reciprocal, dynamic process and a structural construct, determined by a set of internal and external factors, enabling horizontal, vertical, and diagonal information flow throughout the organization by creating synergy among communicators and also effectively and efficiently operating a number of communication categories with the aim to help individuals reach both their own and organizations' communication goals (Blazenaite 2011). Figure 1 presents the determinants of organizational communication.

Krone, Jablin, and Putnam (1987) proposed four perspectives on the communication process: mechanistic, psychological, interpretive-symbolic and system-interaction perspectives, where each of these perspectives models the process of communication from a relatively distinct point of view. From a mechanistic perspective, human communication is viewed as a transmission process in which a message travels across space, through a channel from one point to another. From the mechanistic point of view, events occurring in the channel become the fodder for research and theorizing (Fisher 1978: 112). A mechanistic perspective views communication as a transmission process in which messages travel across a channel from one point to another. The psychological perspective of organizational communication concentrates on explaining the informational environments in which individuals are located and the range of stimuli to which they respond using different conceptual filters. When viewed from an interpretive perspective however, organizational communication consists of patterns of coordinated behaviours that have the capacity to create, maintain, and dissolve organizations (Daft and Weick 1984). The interpretive-symbolic perspective posits that individuals shape their own social reality through communicating. Unlike the interpretive-symbolic approach, research from the systems interaction perspective concentrates on 
external behaviours as the fundamental units of analysis. The locus of communication in the systems-interaction perspective is patterned sequential behavior, meaning the grouping of sequences of communicative behaviours (Jensen 2003).

Figure 1. Determinants of organizational communication

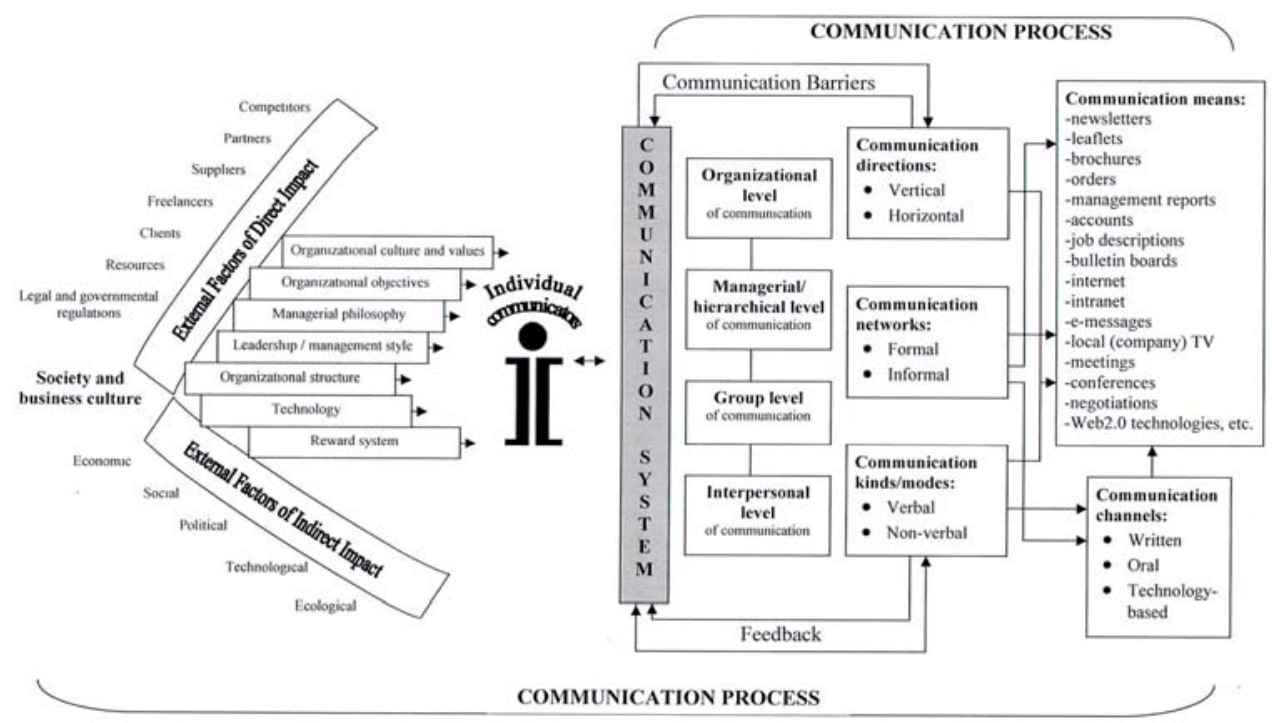

Source: Blazenaite (2011) Effective Organizational Communication

On the other hand, according to Aberg (1990), various processes of communication can be defined, but the key point in the classification is to recognize those processes which are more important and which process is already assigned to existing action, unit or department. These processes are called core processes. Organizational communication core processes can be naturally led from organization communication function. The amount of core processes will vary depending on size of the organization or depending on the emphasis of the task. Aberg (1990) proposed five functions of 
communication in organization and community can affect directly four of those functions. The last one, the social interaction function is not directly under the organization's control.

1. Supporting core operations; communication is necessary for production of commodities - products and services - and for their distribution to customers. Communication is an anchor for the organization's basic operations.

2. Profiling; communication is necessary when a long term corporate, product or manager profile is being created and disseminated. Communication is a necessary function for long-span development.

3. Informing; communication is necessary for purposes of informing internal and external audiences about the developments within the organization. Mechanical or technical 'neutral' information is highly important for and between employees, employers and partners.

4. Socializing; communication is necessary for the socialization of individuals into good organizational citizens.

5. Social interaction is inherent in the human nature. Function includes the idea of informal communication which creates relationships among employees and employers. The primary form of informal communication is face-to-face interaction (but also email and web-base-discussions are important ways nowadays).

Figure 2 presents the theoretical framework for this study which consists of five components.

Theoretical framework of this research contains five parts. The first part focuses on the role of communication in the strategy process which involves the communication function in different stages of the strategy process. The effectiveness and commitment of employees depends largely on their knowledge and their understanding of the strategic issues of the company (Tucker, Meyer and Westerman 1996). The strategic dimension of communication shows itself through the participation in all corporate and departmental decisional processes. Meaningful communication informs and 
educates employees at all levels and motivates them to support the strategy (Barrett 2002). The role of communication function arises as a second part in internal strategy work and as third part the role of communication function is in external strategy. The fourth part of the research is that communication is part of strategic management which refers to management and how the dean defines herself/himself as a communicator of the corporate strategy. Corporate communication strategy is seen to be the outcome of a strategic thinking process by senior communicators and top managers taking strategic decisions with regard to the identification and management of, and communication with, strategic stakeholders (Steyn 2000). The fifth part refers for new technology and its effects on communication process.

Figure 2. Theoretical framework of dean perspectives on the strategic function of communication

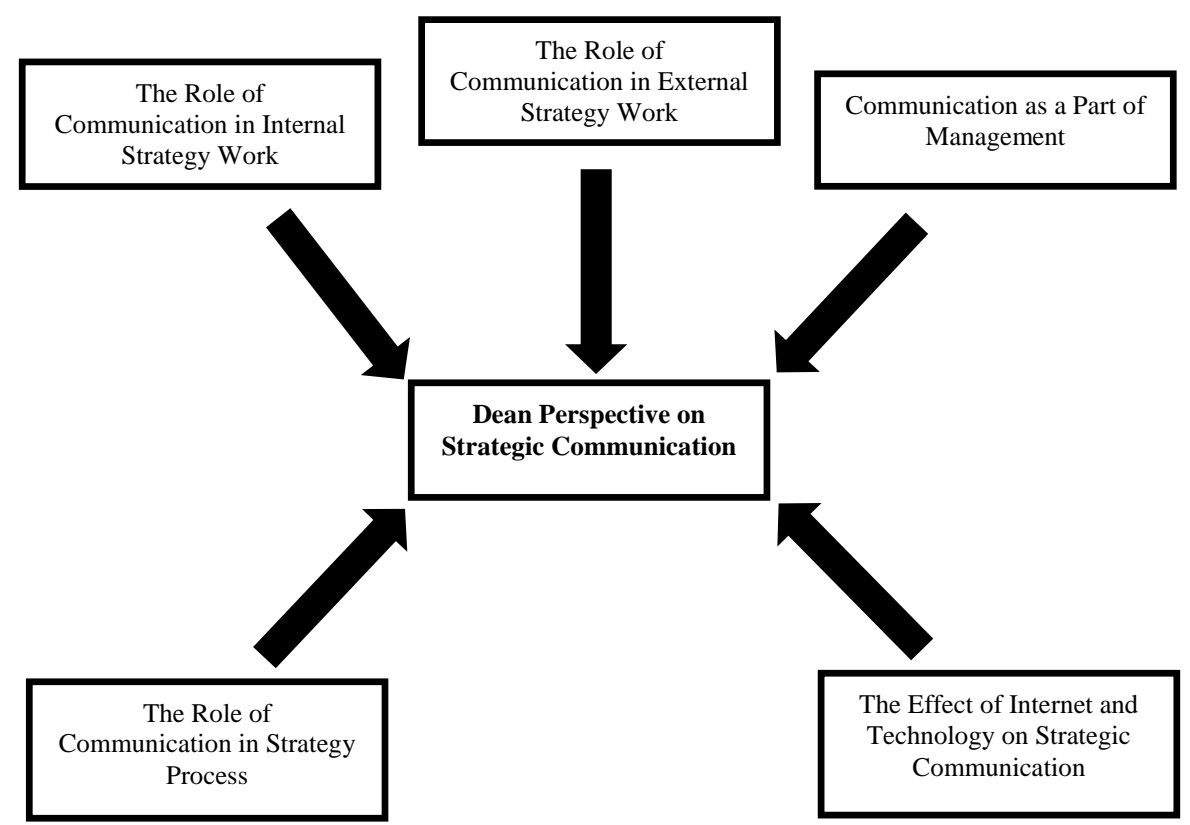




\section{Methods}

This study uses a qualitative research approach involving semi-structured interviews. Qualitative research is best conceived as a family of approaches whose members share commonalities but also possess distinctive differences (Silverman 2001). Methods used by qualitative researchers include interviews, observation, analyzing texts and documents. Of course these methods are quite subjective, but the point of this kind of approach is to read through the answers several times with an open mind and then sort those answers against the researcher's conscience. Critical thinkers might say that the results are just one construction about the truth, and of course it is so, but qualitative research is always tied to the culture of the researcher and it's always just one side of the truth. In qualitative research people are used as research instruments and the researcher relies on the conversation with the people. Qualitative methods bring the researcher into the heart of social life; they extend the noticing, investigating, and analyzing practices of everyday encounters in a systematic manner, offering ways to connect with the communicative worlds that we as researchers are seeking to understand (Silverman 2001).

Qualitative analysis of interviews can range from summarizing the discussion, to identifying themes, to elaborate coding schemes (Fern 2001). The semi-structured interviews were conducted with ten faculty deans of Ege University, Turkey, during April-May, 2013. The duration of the interview sessions lasted between $30 \mathrm{~min}-50 \mathrm{~min}$. Reliability of a qualitative study concerns more the actions and patterns of the researcher than those of the interviewees. The trustworthiness of the interview research data was improved by carefully planning the interview framework and transcribing the interview data as soon as possible.

The interview framework is built upon Aberg's (1990) theory of communication within an organization. Communication on the one hand is seen as a function, while on the other hand it can be seen as a strategic tool that is integrated into strategic management. Additionally the subsequent research themes are integrated to raise themes for the study: as well as 
strategy communication and strategy work aspects and in new technology and communicating in the Internet. The interview framework of the research was conducted as follows:

Theme 1: The role of communication in the faculty management

1. How is communication function constructed in the faculty management?

2. What are the basic activities of communication as internal and external in the faculty management?

3. What are the most critical elements of communication in the faculty management?

4. How can communication make a difference in the organizational management of the faculty?

5. How would you describe the international aspects of the communication in the faculty management?

Theme 2: Communication in strategic management of organization 1. How would you describe strategy in the organizational management of the faculty?

2. How is communication defined as a part of strategic management?

3. What profits does communication have in strategic management?

4. What challenges does communication have in strategic management?

5. How would you define an ideal communication function in strategic management?

Theme 3: The deans and communication

1. How would you describe dean as a communicator in the organization?

2. Can dean as a communicator impact in the strategic management of organizations? If yes, to whom/to what?

3. Have the communication practices/activities/requirements changed? If yes, why and how? 
4. How would you describe the collaboration between the communication function and the dean in the faculty management?

5. How does communication function facilitate the dean duties in the organization?

The data was analyzed inductively, and emergent categories were confirmed and clarified through respondent validation. Findings relating to personal perceptions are presented alongside the major themes of the role of communication in the strategy process, the role of communication in the external and internal work, communication as a part of strategy and new technology and communicating. Once the data were collected, two types of analyses were performed. First, the interviews were tape-recorded and transcribed as case descriptions to which the findings were referred and, subsequently, examined where appropriate. Second, the transcript data was categorized in accordance with a classified theme based on a common ground in typology. The extensive use of transcript, together with the qualitative research analysis, was undertaken to draw out important themes from each interview.

\section{Analysis and Results}

The principal findings which are based on the ten interviews can be listed as follows:

The communication function involves in the strategy process which consists of three levels: planning, implementation and reporting on the success of the organizational strategy. These three levels of strategy implementation were accepted as the most crucial one. The deans perceive that the communication function had to be an expert in the organization strategy. The planning of the communication strategy is particularly recognized as a critical element of general strategy process. Likewise, Blazenaite (2011) introduces the effective communication is the key for keeping an enterprise, as a system of individuals, working together for objectives, successful and integrated. 
The interviewees pointed out that the management style in higher education has altered lately. The role of faculty deans requires some competencies like language and presentation skills in communication process. The general view among the interviewees was that current university management practices require excellent communication competencies. For instance, one interviewee mentioned:

The communication of the dean requires time and effort gradually in order to be effective. Dean is not able to manage the faculty with static communication practices as it might have been possible in the past.

The interviewees defined the communication process within the organization to have two elements as internal and external communication in the organization. According to the interviewees, the two most valuable tasks of internal communication in strategy are to communicate the core concept of strategy and to select the suitable channels to contact internal people and interest groups within the organization. Barrett (2002) also agrees that selecting the appropriate channels to communicate with internal people is a key point for effective management. The role of communication as a motivator in strategy and practicing of the message through different channels are seen as crucial. Besides, all external communication is reported as strategy communication because its principal duty is to organize and sustain the organizational image. The deans describe themselves as the essential element for the effective communication by their personality and interpersonal relationships. One of the interviewees pointed out that motivation was crucial for successful communication as can be regarded from the quotation below:

Inspiring and motivating to faculty to work effectively is a major cornerstone in communicating process rather than only to inform them about the work.

According to the interviewees, four principal advantages and three challenges are described in communication function in the strategy process. The first advantage is that the communication function is defined as a facilitator of harmony and reliability in strategy. The second advantage is 
that, by facilitating the strategic message, communication functions cause a better understanding of strategy. The third advantage helps to enhance organizational identity and image. The fourth advantage of communication function is the reinforcement for the other functions in their tasks to implement the strategy. The communication function is also defined to have three challenges in the strategy. The first challenge is the skill to formulate the messages, and finding the suitable communication channels. The second challenge is the facilitation of the motivation of the faculty members in the organization. The third challenge is described as the use of technology in communication. A majority of the interviewees recognize that the significant advance in management practices is the increasing of choices in communication channels. The general view was that in the future there will be various ways of implementing strategic communication. The interviewees regarded that that besides internet, other similar new technologies would have an effect on communication practices as can be seen from the excerpt:

Mobile phones were used firstly in personal communication at the beginning, but now smart phones are being used in different contexts thus this new paradigm might be used in faculty communication strategically.

According to the interviewees, the personal characteristics are defined as factors that affect the deans' role as a communicator of the strategy. Communication is seen as part of management; therefore, according to the interviewees, since the deans' major duty is to manage according to the organizational strategy. Moreover, if leadership is a key basis for organizational performance, one can safely say communication is the key to effective leadership (Atwater and Waldman 2008). The deans' communication is defined as important element that has an effect on the organizational image. The following quotation presents the perspective of the interviewees about the dean role in faculty image:

The communication of the dean can have an effect on the total image of the faculty. He or she cannot be passive type of person in communication. The dean should be extroverted in communication activities and being reachable." 
Thereupon, a surprising point was that most of the interviewees paid no attention to international views. Despite the importance of communication international views are accepted as vital and essential in the literature (Gratz and Salem 1981), the theme was taken into consideration only in few facts during the interviews. It could be that the international aspect was too obvious to the deans that it was not seen as something that needed special emphasis.

\section{Conclusions}

The research findings reveal that the nature of communication and the function of communication in faculty organization are important and it is perceived as a vital element of management in university. Moreover, the function of communication is notified as a key element to success the strategic plans in the organizational context of universities. Effective organizational communication is important for the ongoing management processes in the universities.

The research displays that the major opinion among the interviewees is that administrative styles have changed in recent periods and that the current higher education management is required to have finest communication, language and presentation skills. Deans also should manage in the international and multi-cultural environment and they should learn new techniques of communication by using new technological changes. A majority of the interviewees have a view that the deans' interactive and interpersonal management skills will play more critical roles in the future.

First, the research suggests that the deans seem to be highly aware of the role of the communication function in faculty management. On the other hand, the findings suggest that in order for the communication function to work effectively, the deans need to value the communication and the cooperation between the faculty members and the deans need to depend on trust. Second, the research proposes that the deans will have his/her own 
type of communicating and that the personality of deans impact on the communication and by that it has an effect on faculty image as well.

\section{References}

Aberg, Leif. 1990. "Theoretical model and praxis of total communications". International Public Relations Review 13 (2): 13-16.

Atwater, Leanne E. and David A. Waldman. 2008. Leadership, feedback and the open communication gap. New York: Lawrence Erlbaum Associates.

Barrett, J. Deborah. 2006. “Leadership Communication: A Communication Approach for Senior-Level Managers". Handbook of Business Strategy 7 (1): 385-390.

Barrett, J. Deborah. 2002. “Change communication: using strategic employee communication to facilitate major change." Corporate Communications: An International Journal 7 (4): 219-231.

Blazenaite, Aukse. 2011. "Effective Organizational Communication: in Search of a System." Social Sciences 4 (74): 84-101.

Daft, Richard L. and Karl E. Weick. 1984. "Toward a model of organizations as interpretation systems." Academy of Management Review 9 (2): 284295.

Eccles, Robert G. and Nitin Nohria. 1991. Beyond the Hype: Rediscovering the Essence of Management. Boston: Harvard Business School Press.

Eisenberg, Eric M. 1984. "Ambiguity as strategy in organizational communication." Communication Monographs 51: 227-242.

Fern, Edward F. 2001. Advanced focus group research. Thousand Oaks CA: Sage Publications.

Fisher, B. Aubrey. 1978. Perspectives on human communication. New York: Macmillan.

Gratz, Robert D., and Philip. J. Salem. 1981. Orgunizational Communication and Higher Education. Washington, D.C.: American Association for Higher Education.

Jensen, Maria. T. 2003.“Organizational Communication - a review.” Research and Development Report (1): 1-106.

Krone, Kathleen J., Fredric M. Jablin and Linda L. Putnam. 1987. "Communication theory and organizational communication: Multiple perspectives." In Handbook of Organizational Communication edited by Fred M. Jablin, Linda L. Putnam, Karlene H. Roberts and Lyman W. Porter. Newbury Park: Sage Publications. 
Lunenburg, Fred C. and Allan O. Ornstein. 2008. Educational administration: Concepts and practices. Belmont, CA: Wadsworth/Cengage.

Mintzberg, Henry. 1973. The Nature of Managerial Work. New York: Harper and Row.

Richmond, Virginia P., and James C. McCroskey. 2009. Organizational communication for survival: making work. Boston: Pearson/Allyn and Bacon.

Silverman, David. 2001. Interpreting qualitative data: Methods for analysing talk, text and interaction. London: Sage.

Steyn, Butch. 2000. "Model for developing corporate communication strategy." Communicare 19 (2): 1-33.

Tucker, Mary L., Gregory D. Meyer, and James W. Westerman. 1996. "Organizational Communication: Development of internal strategic competitive advantage." The Journal of Business Communication 33 (1): 51-69. 